\title{
Know your implant connections
}

\section{Singla S. ${ }^{1}$, Rathee $\mathbf{M}^{2}$}

${ }^{1}$ Dr. Singla Judge Institute of Dental Sciences and Hospital, Panjab University, Chandigarh, India, ${ }^{2}$ Pandit.B.D.Sharma University of Health Sciences, Rohtak, Haryana, India.

\begin{abstract}
Background: Implant abutment connection is the point of transition from surgical to prosthetic phase and is the primary determinant of strength and stability of implant supported prosthesis. There are a huge number of implant designs in the market, all claiming to have better clinical results.

Materials and Methods: A search of electronic database from 1990 to 2014 in Pubmed search engine using key words like 'Implant-abutment interface', 'Abutment connection', 'External Hex', 'Internal hex', 'Morse taper' alone or in combination was performed for critical evaluation of contemporary implant designs.

Result and Discussion: There is a pleothora of implant designs vying for supremacy in the market. This review informs the clinicians regarding inherent differences in design characteristics and clinical applications of various implant-abutment connections so as to enable them to chose a design which ensures simplified restorative phase, minimal complications and cost effectiveness.
\end{abstract}

Keywords: Implant-abutment interface, abutment connection, external hex, internal hex, morse taper.

\section{INTRODUCTION}

Dental implant-abutment systems are used as anchors to support single or multiunit prostheses for partially or fully edentulous patients. A dental implant system consists of a fixture that is surgically implanted in bone and a transmucosal component that mates with implant and connects it to prosthetic crown. Implant abutment connection (IAC) is the point of transition from surgical to prosthetic phase and is primary determinant of strength and stability of the implant supported prosthesis. Over the years, different IAC have been developed with an aim to reduce stress on the prosthetic component and on bone-implant interface and provide adequate prosthetic stability. It is required to serve the purpose of antirotation, prosthetic indexing and also resist bacterial penetration. This review aims to critically describe different options of implant abutment connections, discuss their biomechanical rationale, clinical use, advantages and drawbacks.

\section{MATERIAL AND METHODS}

Contradictions found in literature and the diversity of implant connection options creates doubts while choosing suitable connection. A Medline search was

\section{Correspondence: Dr. Shefali Singla}

House No. 2863, Sector 42-C, Chandigarh, India.

PIN - 160036

E- mail: shefali_singla@yahoo.com conducted from 1990 till 2014 using keywords like 'Implant-abutment interface', 'Abutment connection', 'External Hex', 'Internal hex', 'Morse taper' alone or in combination. Option of related articles was also utilized. Related English language publications were reviewed excluding case reports and individual product based articles. An analysis of evolution of various designs from conventional External Hex to Cone Screw implants and Platform Switch mode was made to provide the clinicians with an overview of various commercially available Implant abutment interfaces (IAI).

\section{LOCATION OF CONNECTION}

IAC is the point of contact between the surgical and prosthetic phase and is required to provide adequate joint strength, rotational stability, prosthetic indexing, and resistance to microbial penetration. External connection involves a geometric projection extending above implant body (Fig.1) while in Internal

Figure 1: External Hex Connection

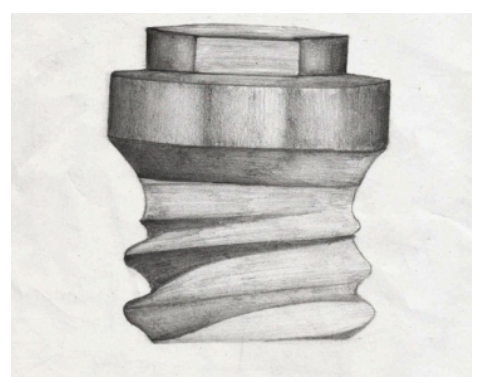


connection, mating components are recessed into the implant body (Fig.2). IAC can be further characterized as a slip fit joint (passive connection) where slight space exists between the mating parts e.g. external or internal hex, or a friction fit joint where mating components are literally forced together e.g. Morse taper and cone screw connection (Table 1). Mating

Figure 2: Internal hex connection

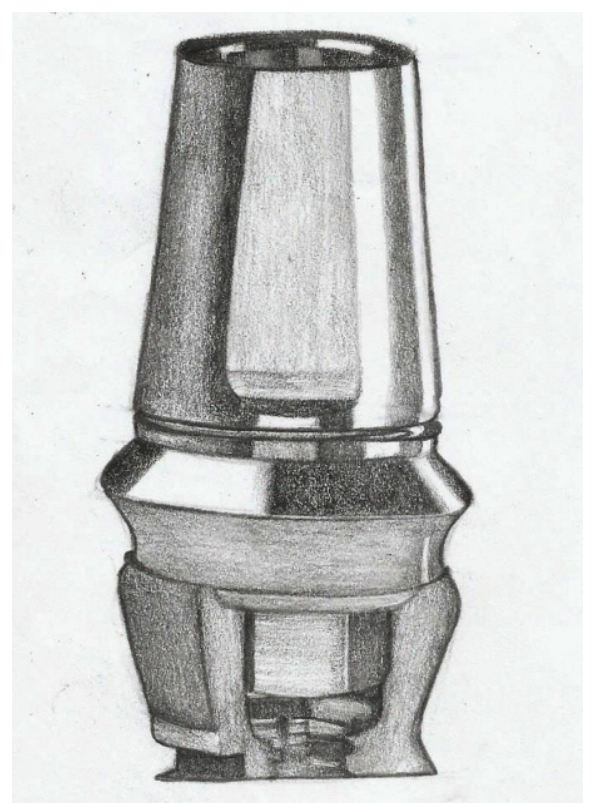

surfaces can exist as a butt joint consisting of two right angle flat surfaces contacting or bevel joint where surfaces are angled internally or externally.
An antirotational and indexing feature incorporated in mating surfaces can be a hex, octagon, cone hex, cam, spline or trichannel.

\section{External hex connection}

Initial $0.7 \mathrm{~mm}$ tall external hex connection with a butt joint was introduced by Branemark as a coupling and torque transfer device. ${ }^{1}$. It has retrievability and compatibility among different systems and has broad number of prescribed clinical applications reflected in long term follow $\mathrm{up}^{2}$. It promotes lower stress concentration around implant as compared to internal hex design when splinted to natural teeth. Major drawback is screw loosening (reported incidence is 6$48 \%$ ) and fatigue fracture due to short hex height and limited engagement leading to microvements and joint instability. Other disadvantages are reduced prosthetic space, limited transition depth for esthetic restoration and requirement of platform specific healing collars, abutments, transfer copings and analogs, which increases inventory costs and complexity.

Limitations of external hex became more evident when its application was extended to single missing tooth or partially edentulous arches and led to major modifications in order to avoid prosthesis rotation. Taller (0.7 to $1.2 \mathrm{~mm})$ and wider (2.0-3.4mm flat to flat width) connections were attempted to increase the fulcrum arm and improve the abutment screw engagement. Different manufacturers have

Table 1: Types of Implants based on location and mode of connection

\begin{tabular}{|c|c|c|}
\hline $\begin{array}{l}\text { Location } \\
\text { of } \\
\text { connection }\end{array}$ & Slip fit connection & Friction fit connection \\
\hline $\begin{array}{l}\text { External } \\
\text { Connection }\end{array}$ & $\begin{array}{l}\text { External hexagon } \\
\text { External Octagon (ITI implants) } \\
\text { External Spline (Calcitek) }\end{array}$ & $\begin{array}{l}\text { Tapered hex with } 1.5^{\circ} \text { taper } \\
\text { (Swede Vent TL by Paragon } \\
\text { implants) }\end{array}$ \\
\hline $\begin{array}{l}\text { Internal } \\
\text { Connection }\end{array}$ & $\begin{array}{l}6 \text { point internal hex (Core Vent) } \\
12 \text { point Double Internal hex } \\
\text { (3i Osseotite) } \\
\text { Internal cylinder hex } \\
\text { InternalOctagon (Omnilock,Sulzer } \\
\text { Calcitek) } \\
\text { Internal Spline (Neoss Implants) } \\
\text { Trichannel Implant (Replace Select } \\
\text { by Noble Biocare) }\end{array}$ & $\begin{array}{l}\text { Internal Hex by Zimmer } \\
\text { and Biohorizon } \\
\text { True Morse Taper } \\
\text { (Bicon Implants) } \\
\text { Cone Screw Connection } \\
\quad 8^{\circ} \text { Cone screw (ITI Straumann, } \\
\text { Osteo Ti,3i TG) } \\
\quad 11.5^{\circ} \text { Cone screw } \\
\text { (Astra Tech) } \\
5.7^{\circ} \text { Cone screw }\end{array}$ \\
\hline
\end{tabular}


introduced modifications in hex design. Tapered Hex with $1.5^{\circ}$ taper to create friction fit between abutment and implant was introduced by Swede-Vent TL (Paragon Implant Co). Friction fit of mating components in this design significantly reduced the rotational freedom at IAC, thus decreasing incidence of screw loosening ${ }^{5}$. External Octagon (ITI implants), a tall 8 sided external connection allowing 45 degree rotation while placement of abutment over the fixture, did not become popular because of incompatibility with angled abutments and little rotational resistance at IAC due to its almost circular geometry. External spline dental implant introduced in 1992 by Calcitek, has 6 spline teeth projecting outward from implant body and fitting into 6 grooves between projections from corresponding abutments and exhibits decreased screw loosening, minimal rotational movement and load relief to screw.

Implant components are held in place by screws. Tightening torque elongates the screw, generating tensile force called preload which is responsible for clamping force between two parts ${ }^{7}$. Preload should be $75 \%$ of maximum external force trying to separate the joint $^{8}$. Modifications in screw design have been attempted to maximize preload and reduce loss of initial tightening torque to friction'. Screws with flat head seat and long stem length with 6 threads have optimal elongation. Flat head screw distributes forces more evenly within the threads and screw head whereas in a tapered screw, forces are distributed to the head rather than fixation screw. Tapered screw also reduces the clamping force and tension in screw threads $^{10}$. The greater the diameter of screw, the more the preload and clamping force ${ }^{10}$. Gold screw has better preload (almost twice) but lower yield strength than Titanium alloy screw ${ }^{11}$. Screws coated with TorqTite (Teflon coating on Ti screw) and Gold-Tite (pure gold coating) gain preload by reducing friction and better fixation'. Every screw design has a specific preload/torque relationship depending on the design of the screw head and material used ${ }^{12}$. Implant surfaces are microscopically rough and so are not in complete contact with one another. Application of initial tightening torque flattens this roughness, bringing the surfaces together, causing settling effect. The extent of settling depends on initial surface roughness, surface hardness, and magnitude of loading forces. Screw loosening occurs when this settling exceeds elastic deformity of screw because there are no more contact forces to hold it in place $^{13}$.
Studies have reported a 2-10\% loss in initial preload as a result of Embedment relaxation/settling effect ${ }^{14}$. Screws should be routinely retightened 10 minutes after initial torque application ${ }^{11,15}$.

\section{Internal Connection}

This revolutionary interface design was developed to address the clinical complications of external connection. Initial internal connection (Core vent implant introduced by Niznick) had a $1.7 \mathrm{~mm}$ deep hex below $0.5 \mathrm{~mm}$ wide, $45^{\circ}$ bevel $^{16}$. The mating components are deep within the implant body, shifting the abutment implant fulcrum to the middle of implant resulting in better stress distribution and improved prosthetic screw stability. It is now available as Screwvent implant manufactured by Zimmer. Main advantage of this connection lies in dissipation of lateral loads deeper within the implant and its long internal wall engagement which shields the screw and creates a stiff, unified body, resisting micro movements at IAC, hence achieving better joint strength and stability. Levin reported a screw loosening incidence as low as $3.5 \%{ }^{[17]}$. Better esthetics can be achieved due to reduced vertical height platform for restorative components and provides adequate transition depth from IAC to gingival margin so as to permit a smooth buccal contour and a better emergence profile. It has greater potential for obtaining microbial seal due to precise fit between mating parts. Weaker link in internal connection is bone rather than prosthetic screw because of more stress concentration in bone around implants ${ }^{18}$. Over the years, internal connections have diversified into numerous designs in an attempt to achieve better microbial seal and joint stability and a choice among them is more of a personal preference and availability rather than an informed decision.

Internal slip fit connections have an internal geometrical antirotational feature like hexagon, octagon, spline or trichannel. A 6 point internal hex has a $1.2 \mathrm{~mm}$ deep hex recessed into implant body which allows abutment positioning over implant at every $60^{\circ}$ rotation i.e. at 6 different positions eg. screw vent (centrepulse) is a tapered screw vent implant with $1.7 \mathrm{~mm}$ deep internal hex connection. FriadentFrialit-2 is a stepped cylindrical implant providing better axial as well as lateral load distribution ${ }^{19} .12$ point double internal hex (3i Osseotite Certain) has $4 \mathrm{~mm}$ deep double internal hex providing better stress distribution and allows abutment positioning over implant at every $30^{\circ}$ rotation which is more beneficial 
in case of angled abutment. It has the unique feature of audible click (Quick seal connection) indicating complete seating of abutment over implant and availability of narrow abutment diameter in comparison to implant diameter provides platform switching effect. Internal cylinder hex has up to $5 \mathrm{~mm}$ deep hex within implant body which significantly enhances joint stability by resisting bending forces in comparison to external hex or even $1.5 \mathrm{~mm}$ deep internal hex ${ }^{20}$. Internal octagon implant was introduced by Omnilock, Sulzer Calcitek and had 8 sided internal geometry similar to a circle in profile ${ }^{1}$. It allowed abutment orientation over implant at 4 different positions i.e. at every $45^{\circ}$ but did not gain popularity because of minimal rotational and lateral resistance during function.

Neolinks, the internal spline connection (Neoss implants) with six splines/teeth projecting outward from abutment and fitting snugly into corresponding grooves recessed in implant body (Figure 3), ensure limited micromotion and reduced screw loosening. Narrower abutment diameter than implant platform provides benefit of platform switching.

Internal tripod connections have triangular internal geometry. Trichannel implant introduced by Nobel Biocare has three lateral channels projecting from the abutment into the implant body as antirotational feature (Figure 4 ). It has a $1.2 \mathrm{~mm}$ deep slip-fit joint and allows only 3 possible positions for placement of abutment over implant (120' rotation only). Cam tube available with Camlog implant system (AlatechTechnologies) is a tube in tube

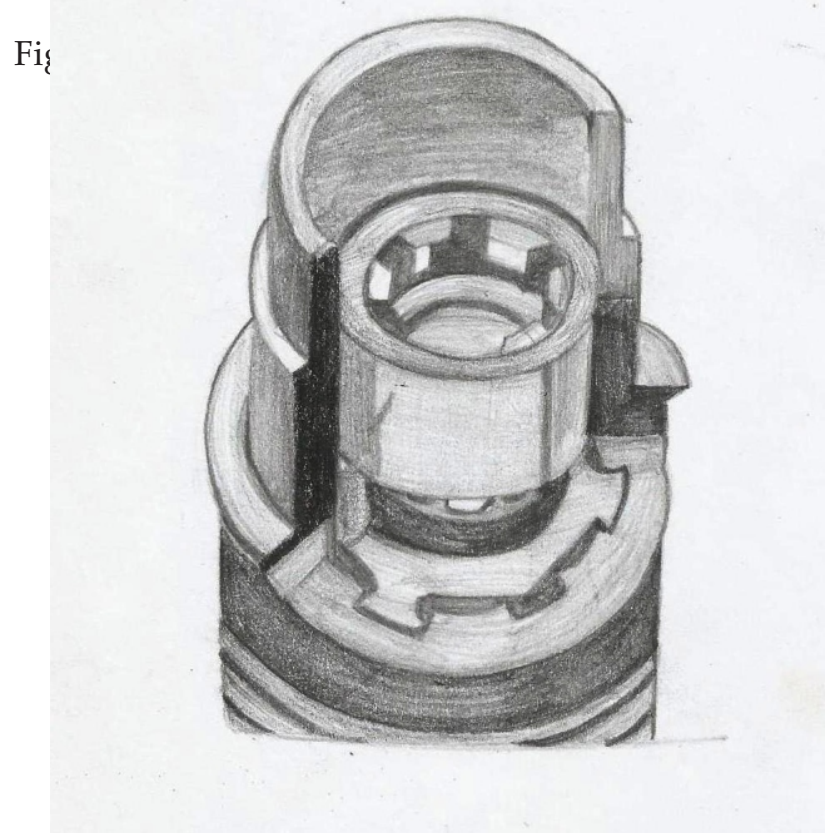

connection where three cam tubes are seated within implant body. Its $5.4 \mathrm{~mm}$ deep internal connection ensures minimal screw loosening and excellent microbial seal. Keystone connection is another modification of trichannel connection with 6 lobes rather than 3 , in an internal slip fit joint .

Internal friction fit/interference fit connections have no space existing between mating components and abutment actually wedges into the implants internal recess due to friction, resulting in a virtual 'cold weld' between the two which provides superb microbial seal and joint stability.

\section{Figure 4: Trichannel connection}

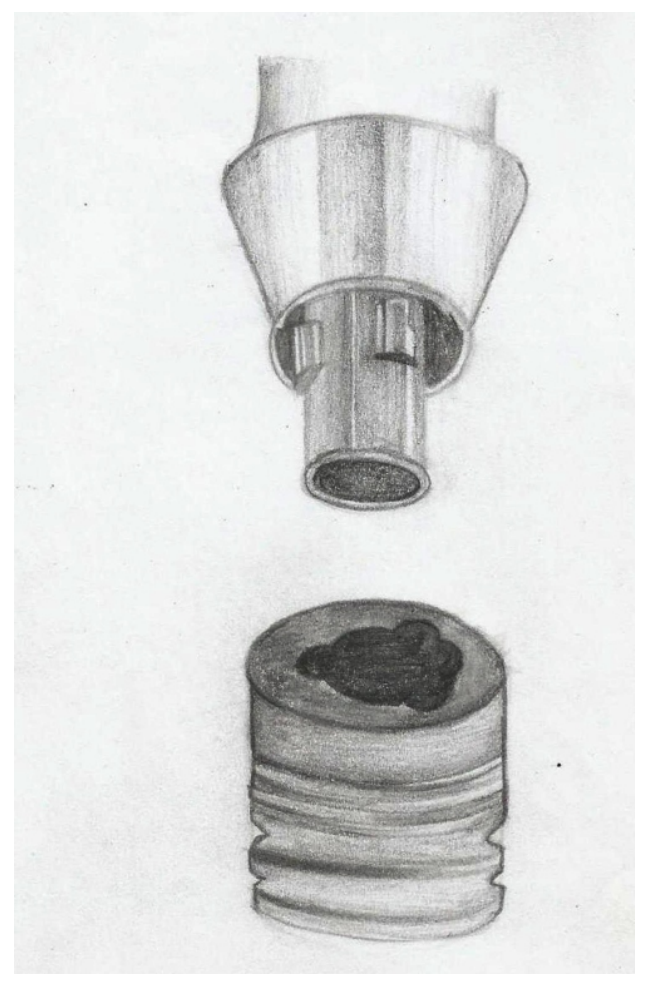

Most implant companies using internal hex in a slip fit connection eventually switched over to friction fit so as to gain benefits of cold welding between abutment's tapered connection and internal surface of implant e.g. $1.5 \mathrm{~mm}$ deep internal hex connection by Zimmer (Screwvent) and Biohorizon. Zimmer implants exhibit $0^{\circ}$ rotational misfit when tightened to $30 \mathrm{Ncm}^{1}$. Biohorizon implant has additional Spiralock technology of thread design for screw shielding.

Morse taper/locking taper (cone within a cone) has a conical projection from abutment tightly fitting into precisely manufactured conical recess in implant body (Figure 5). Mechanical friction between external conical wall of abutment and internal wall of implant 
locks them into a cold welded stability ${ }^{21,22}$ eliminating rotation and subsequent screw loosening and allows for even stress distribution within the implant, abutment and respective screw $^{22,23}$. It has superior mechanical stability as compared to buttjoint designs ${ }^{24}$ with 3.65 to $5.3 \%$ reported incidence of screw loosening ${ }^{17}$. Screwing torque required is less as compared to external/internal hexes ${ }^{25}$ and also provides adequate biological seal ${ }^{26}$. Conical connection inherently provides platform switching by medializing the IAC.

Degree of morse taper is percentage unit that reflects the shaft length relative to radius of shaft. e,g. an 8 degree morse taper will have

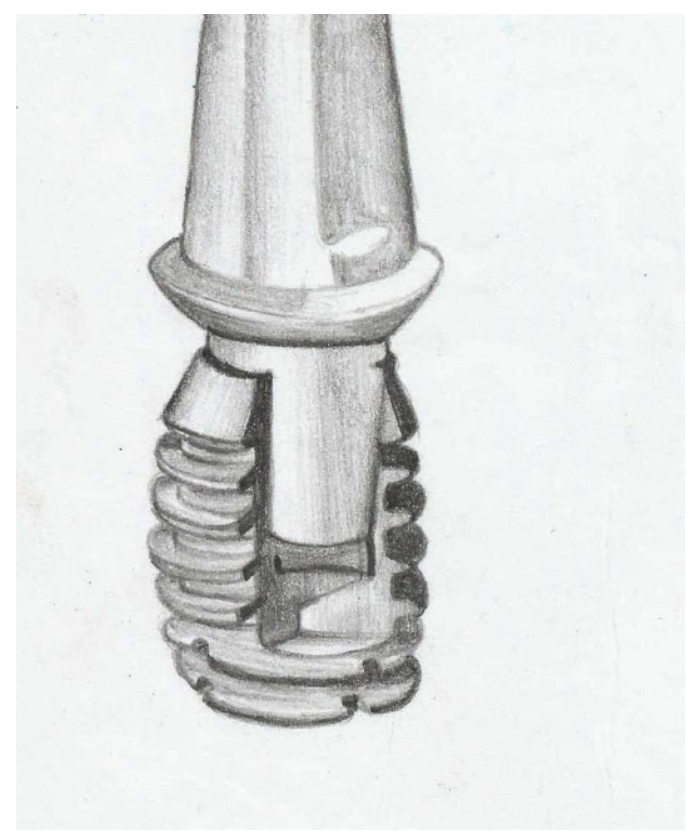

a radius increase of $8 \mathrm{~mm}$ for $100 \mathrm{~mm}$ shaft length increase. Morse taper has further evolved as true morse taper and Cone Screw. True morse taper connection relies purely on mechanical friction between two mating cones (with 2-4 degree taper) for creating a seal between implant and abutment without the need for a retaining screw. e,g. Bicon implant. It has $1.5^{\circ}$ locking taper without threads and as abutment is tapped into implant's tapered recess, high contact pressure breaks surface oxide layers causing cold welding at implant abutment interface. Abutment can fit anywhere in $360^{\circ}$ of implant recess, allowing prosthesis to be positioned into an ideal orientation with excellent microbial seal and stable connection.

\section{Cone screw connection}

Is an internal, tapered connection introduced by Wiskott and Belser, utilizing the self-locking principles of a morse taper with a retaining screw connecting the abutment to the implant (Figure 6). First manufactured by ITI Straumann ${ }^{27}$, it allows repositioning of the abutment over implant and precise transfer of implant position to master cast. It has one transfer system and one analog requirement reducing inventory cost. $8^{\circ}$ cone screw tapered connection by ITI-Straumann introduced an internal hexagon in the middle of the morse taper. SynOcta by Straumann has internal octagon as antirotational feature. Other systems using $8^{\circ}$ cone screw are combi implant by Osteo-Ti, Avana, 3i TG. Astra Tech uses 11.5 taper with a dodecagonal antirotational geometry. Its microthreaded conical neck has TiO blast surface which prevents stress concentration at crestal bone margin. Ankylose (Densply) introduced by Nentwig and Moser $^{28}$ has $5.7^{\circ}$ morse taper. It has indexed and non indexed models. Non indexed connection is like a true morse taper and has obvious prosthetic advantage of possible abutment connection in any position.

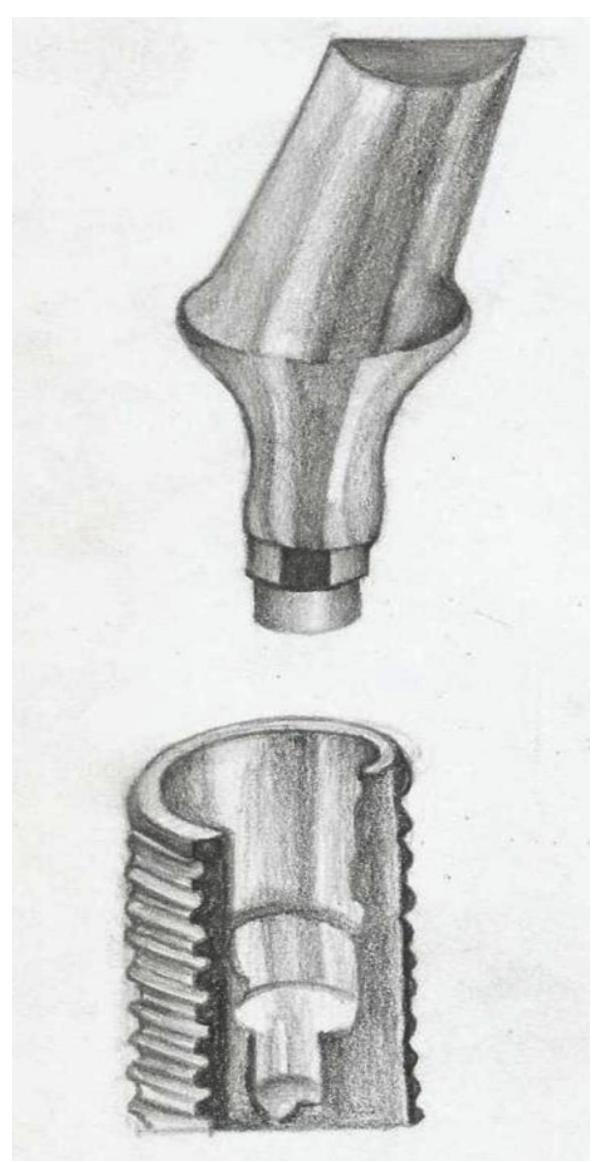


Platform switching is an IAC modification to control crestal bone loss around dental implants. This term was coined by Gardner in 2005 and expanded by Lazzara in $2006^{29,30}$. This concept uses prosthetic abutments with reduced diameter in relation to implant platform diameter, thus moving the implant abutment junction and supposedly the inflammatory reaction medially, away from the crestal bone and may thus, minimize crestal bone loss. Step, created between abutment and implant allows the biologic width to be established horizontally. This means, less vertical bone resorption is required to compensate for biologic seal. Significant decrease in crestal bone loss was noted if implant abutment diameter difference was greater or equal to $0.4 \mathrm{~mm}^{31}$. It can reduce crestal bone loss around $1.56 \pm 0.7 \mathrm{~mm}^{32,33}$ and facilitates superior aesthetics with preservation of interdental papilla, better bone-implant contact and improved primary stability. It necessitates components with similar design and enough soft tissue depth $(>3 \mathrm{~mm})$ to develop adequate emergence profile.

Platform switching can be achieved by using abutments with a diameter smaller than the implant neck or body width, using an implant design where neck diameter is increased with respect to the implant body width, using inherently platform switched implants and conical emergence abutments freeing extension of the implant platform between 0.5$0.75 \mathrm{~mm}$ or bone platform switching which involves an inward bone ring in the coronal part of the implant that is in continuity with the alveolar bone crest ${ }^{34}$.

\section{CONCLUSION}

IACs have progressed from early external hex connection to more advanced internal connections which are dominating the market today, but there is no solidifying evidence pointing to a single best connection type. The external hexagon is indicated for multiunit restoration. On the other hand, the internal hexagon and the morse cone are more favorable in single-unit restorations and aesthetic regions. The platform switching concept is adequate under reduced prosthetic space (mesiodistal) to preserve the crestal bone and the interdental papillae. All types of prosthetic platforms provide high success rate of the implant treatment by following a strict criteria of their indication and limitations. This paper has described various commercially available IAC, with an aim to help readers in making an informed decision regarding choice of implant system and connection design.

\section{REFERENCES}

1. Binon PP. Implants and components: entering the new millennium. Int J Oral Maxillofac Implants 2000;15:76-94.

2. Maeda $Y$, Satoh T, Sogo M. In vitro differences of stress concentrations for internal and external hex implant-abutment connections: a short communication. J Oral Rehabil 2006;33:75Y78

3. Silva EF, Pellizzer EP, Mazaro JVQ, Garcia JIR. Influence of the connector and implant design on implant-tooth-connected prostheses. Clin Implant Dent Relat Res.2009;12:1-9.

4. Butz F, Heydecke G, Okutan M, Strub JR. Survival rate, fracture strength and failure mode of ceramic implant abutments after chewing simulation. J Oral Rehabil. 2005; 32:838-843.

5. Niznick GA. The implant abutment connection: the key to prosthetic success. Compend Cont Educ Dent 1991;12:932-937.

6. Binon PP. The spline implant: design, engineering and evaluation. Int J Prosthodont 1996:9;419-433.

7. Tsuge $\mathrm{T}$ and Hagiwara Y. Influence of lateraloblique cyclic loading on abutment screw loosening of internal and external hexagon implants. Dental Materials Journal.2009;28:373381.

8. McGlumphy EA, Mendel DA, Holloway JA. Implant screw mechanics. Dent Clin North Am. 1998 ;42(1):71-89.

9. Park CI, Choe HC, Chung CH. Effect of surface coating on the screw loosening of dental abutment screws. Metals and Materials International.2005;11:449-456.

10. Misch CE. Dental implant prosthetics, Elsevier Mosby Publication.2005

11. Haack JE, Sakaguchi RL, Coeffy JP. Elongation and preload stress in dental implant screws. Int J Oral Maxillofac Implants.1995;10:529-536.

12. Finger IM, Castellon $P$, Elian N. The evolution of external and internal implant/abutment connections. Pract Proced Aesthet Dent 2003;15(8):625-632.

13. Jorneus L, Jemt T, Carlsson L. Loads and designs of screw joints for single crowns supported by osseointegrated implants. Int J Oral Maxillofac Implants.1992;7:353-359. 
14. Sakaguchi RL, Borgersen SE. Nonlinear contact analysis of preload in dental implant screws. Int J Oral Maxillofac Implants.1995;10;295-302.

15. Winkler S, Ring K, Ring JD, Boberick KG. Implant screw mechanics and the settling effect:overview. J Oral Implantol.2003;29;242-245.

16. Niznick GA. The Core-Vent ${ }^{\mathrm{TM}}$ implant system. The evolution of the osseointegration implant. Oral Health 1983;73:13-317.

17. Levine R, Clem D, Wilson T, Higginbottom F, Solnit G. Multicenter retrospective analysis of the ITI implant system used for singletooth replacement: results of loading for 2 or more years. Int J Oral Maxillofac Implants 1999;14:516-520.

18. Nishioka RS, Vasconcellos LGO, Nishioka LNBM. External hexagon and internal hexagon in straight and offset implant placement: strain gauge analysis. Implant Dent 2009;18:512-520.

19. Krennmair G, Schmidinger S, Waldenberger O. Single-tooth replacement with the Frialit-2 system: a retrospective clinical analysis of 146 implants. Int J Oral Maxillofac Implants . 2002;17:78-85.

20. Mollersten L., Lockowandt P, Linden L. Comparison of strength and failure mode of seven implant systems: an in vitro test. J Prosthet Dent.1997;78(6):582-591.

21. Sutter F, Weber HP, Sorenson J, Belser U. The new restorative concept of the ITI dental implant system: design and engineering. Int J Periodont Rest Dent. 1993; 13: 409-431.

22. Merz BR, Hunenbart S and Belser UC. Mechanics of the implant-abutment connection: an 8-degree taper compared to a butt joint connection. Int J of Oral Maxillofac Implants.2000; 15: 519-526.

23. Norton MR. An vitro evaluation of the strength of an internal conical interface compared to a buttjoint interface implant design. Clin Oral Implants Res 1997;67:236-245.
24. Hansson S. A conical implant-abutment interface at the level of the marginal bone improves the distribution of stresses in the supporting bone. Clin Oral Implants Res. 2003 ; 14 :286-293.

25. Steinebrunner L, Wolfart S, Ludwig K and Kern M Implant abutment interface design affects fatigue and fracture strength of implants. Clin Oral Impl Res.2008;19:1276-1284.

26. Sullivan R. Wide implants for wide teeth. Dent Econ.1994;84:82-83.

27. Ding TA, Woody RD, Higginbottom FL, Miller BH. Evaluation of the ITI Morse taper implant/abutment design with an internal modification. Int J Oral Maxillofac Implants 2003;18:865-872.

28. Nentwig GH. The Ankilos implant system: concept and clinical application. J Oral Implantol 2004;30:171-177.

29. Gardner DM. Platform switching as a means to achieving implant esthetics. N Y State Dent J 2005;71:34-37.

30. Lazzara RJ, Porter SS. Platform switching: a new concept in implant dentistry for controlling post restorative crestal bone levels. Int J Periodontics Restorative Dent 2006;26:9-17.

31. Atieh MA. Platform switching for marginal bone preservation around dental implants: a systematic review and meta-analysis. J Periodont .2010;81:1350-1366.

32. Nebot XV, Ciurana XR, Alonso CR and Torres SM. Benefits of an implant platform modification technique to reduce crestal bone. Implant Dent 2006;15:313-320.

33. Canullo L, Rasperini G. Preservation of periimplant soft and hard tissues using platform switching of implants placed in immediate extraction sockets: a proof-of-concept study with 12 to 36 month follow-up. Int J Maxillofac Implants 2007;22:995-1000.

34. Carinci F, BrunelliG, Danza M. Platform switching and bone platform switching. J Oral Implantol 2009;35:245-250. 